\title{
International Cancer Education Conference: Using Cancer Education to Address Social Determinants of Health
}

\section{Maria Curcio Bishop ${ }^{1}$}

Accepted: 24 October 2020 / Published online: 30 October 2020

(C) American Association for Cancer Education 2020

The 2020 International Cancer Education Conference was held from October 13 to October 15, 2020. Due to the COVID-19 pandemic, the conference was canceled in Lexington, Kentucky, and converted to a virtual meeting. The 3-day event hosted by the American Association for Cancer Education (AACE), the European Association for Cancer Education (EACE), and the Cancer Patient Education Network (CPEN) featured preconference workshops, plenary sessions, poster presentations, roundtable discussions, and concurrent sessions. The theme of the workshop was "Using Cancer Education to Address Social Determinants of Health." Participants registered for the virtual conference represented multiple countries, including Canada, the UK, Jordan, Pakistan, and the USA. I thoroughly enjoyed attending the conference and thought I would share some highlights with you.

The conference began with preconference workshops. These workshops offered a wide variety of interactive options. Dr. Ewa Szumacher, past president of AACE, and her colleagues presented "Essential Skills in Cancer EducationLeading and Influencing Change in Cancer Education." The workshop included presentations about various types of leadership styles, case reports, and 3-min reports from the participants describing proposed projects. Following the workshop, the participants and their assigned mentors will continue to work on their projects throughout the year.

A National Cancer Institute (NCI) training workshop, "NCI's Support for Cancer Education Across the Academic Lifespan: R25 and UE 5 Programs," was also offered. The participation of our NCI colleagues at our annual conferences is always much appreciated and very well received. The

Maria Curcio Bishop

mbishop@email.arizona.edu

1 Section of Hematology and Oncology, University of Arizona Cancer Center, PO Box 245024, 1515 N Campbell Ave,

Tucson, AZ 85724-5024, USA workshop provided many important instructions related to successful R25 grant preparation, and a question-and-answer session following the workshop generated interactive discussions.

Several other engaging workshops were offered, including Difficult Conversations in Health-Literate Care, Best Practices in the Development of Web-Enabled Cancer Patient Education Tools for Improved DecisionMaking, and Advancing Antiracist Psychosocial Care to Address Financial Hardship in Adolescent and Young Adult Oncology. I received several comments about the exceptional quality of the workshops throughout the conference.

Prerecorded lectures followed by Zoom interactive sessions were offered daily. The Samuel C. Harvey Lecture was the first lecture of the conference. The Samuel C. Harvey Award was established in 1951 to honor Dr. Harvey, former chair of the Department of Surgery at Yale University's School of Medicine, where he introduced active learner-centered education. It is awarded annually by the AACE President for leadership in cancer education. This year's recipient was Dr. Ivan Silver from the Centre for Addiction and Mental Health, University of Toronto, who has been a mentor to several of our members. Dr. Silver presented the Samuel C. Harvey Lecture, "Learning Conversations-A Window to a World of Enhanced Cancer Education." His excellent plenary presentation provided several innovative approaches to address social determinants of care for cancer patients.

In addition to Dr. Silver's Samuel C. Harvey Lecture, six plenary sessions addressed topics related to the theme of the conference, which enriched our understanding of disparities, eLearning, social determinants of health, and the impact of the COVID-19 pandemic. Dr. Webb Hooper from the National Institute of Minority Health and Health Disparities (NIMHD) started off the conference with the first plenary session, "Cancer Education in the Age of COVID-19: Disparities, 
Pandemics, and Infodemics." Her lecture was followed by the following:

- Diversity in Cancer Training-Transforming Challenges into Opportunities - Dr. Alison Lin, NCI

- Using Cancer Communication to Address Social Determinants of Health-Dr. Robin Vanderpool, NCI

- Cancer Disparities and Treatment Equity: Removing Barriers to Cancer Care in our Community-Dr. Chris Lathan, Dana-Farber Cancer Institute

- The Colors of COVID-19: Confronting Health Disparities During a Global Pandemic-Dr. Stephen Thomas, University of Maryland Center for Health Equity

Our European Association for Cancer Education (EACE) colleague Dr. Charles Kelley presented the EACE Plenary Lecture, "Teaching and Learning in Cancer in a Time of COVID." e-Learning has been widely used by Dr. Kelly and his colleagues for several years at the Northern Centre for Cancer Care, Newcastle upon Tyne. He shared his experiences with the audience and addressed questions about the benefits and limits of e-learning. Dr. Kelly's comprehensive lecture provided several examples of the impact of COVID-19 on all levels of medical education, from undergraduate to postgraduate degrees.

Concurrent sessions were offered from Tuesday through Thursday. These sessions addressed such topics as palliative care education, culturally focused storytelling, COVID-19 and cancer communication, cancer treatment for individuals with autism, and access to clinical trials.

Posters were also available for viewing throughout the conference.

Roundtable discussion groups were facilitated by CPEN and AACE members. Students who attended the conference did a great job as cofacilitators. We look forward to having them as members of our organizations in the future! Roundtable topics included the following: health literacy, using virtual tools, e-health and telehealth, international health education, education and training program coordination, and addressing health disparities.

Another very well received and touching component of the conference was the patient panel. Participants diagnosed with cancer honestly and bravely discussed how their personal identities and backgrounds affected their experiences navigating cancer care and health systems. The participants offered a look at the human side of cancer care and reminded us of the reason we do the work we do. We extend a very special note of appreciation to the panel for joining us, providing their survivorship perspectives, and teaching us so much.

The Margaret Hay Edwards Achievement Medal was established in 1986 in honor of Dr. Margaret Hay
Edwards to recognize sustained outstanding contributions to cancer education. This honor is awarded annually by the AACE Advisory Committee to individuals who have made noteworthy contributions to cancer education. The recipient of this year's award was Dr. Otis Brawley. Dr. Brawley was recognized for his work in medical education addressing the diversity of care and access to healthcare services by cancer patients of low socioeconomic status. He inspired us with his comments about the importance of addressing social determinants of health in the healthcare system and being strong advocates for equitable access to healthcare services.

The R. Davilene Carter Presidential Prize for Best Manuscript was awarded to Dr. Janet Papadakos and colleagues for their manuscript "Cost Analysis of Patient Education Materials Development." Their manuscript was recently accepted for publication in the Journal of Cancer Education.

AACE grants in Research, Education, Advocacy, and Direct Service (READS) are awarded semiannually by the AACE Awards and Scholarships Committee to active AACE members in good standing who champion the highest standards for global cancer education through evidence-based practices to achieve quality outcomes. The grants are intended to assist AACE members in becoming more involved in research, education, teaching, and advocacy as well as direct service on national and international levels. The program was established in 2019 to support AACE members in their cancer education goals. The February 2020 recipients were Dr. Meredith Giuliani and colleagues for their project "Assessing the Comprehensive Needs of Informal Caregivers of Cancer Patients Towards the Development of a Skills Training Program." The two June 2020 recipients were Dr. Shine Chang and colleagues for their project "Focus Groups in India about Role of Education/Training on Cancer Prevention Uptake" and Dr. David Mac and colleagues for their project "The Effects of Residency Curriculum Change on Near-Peer Mentorship of Radiation Oncology Residents."

During the AACE Business Meeting, new members of the Academy of Fellows were announced. The Academy of Fellows was established to work with the AACE Executive Board to identify trends in cancer education and training, foster innovation and collaboration, and enhance the critical importance of cancer education in the rapidly changing cancer care environment. The new inductees are Dr. Shine Chang, Dr. Suzanne Gronemeyer, Ms. Ginger Krawiec, Dr. Linda Krebs, Dr. Georgia Sadler, and Dr. Ewa Szumacher.

The first virtual International Cancer Education Conference was a success. The experience that was gained 
organizing this event will allow us to augment our future conferences with new, innovative opportunities. We greatly appreciate all the work that the planning committee and our colleagues at Custom Management Group (CMG) did to organize this conference. We are also very grateful for our presenters who shared their inspirational work and enhanced our understanding of social determinants of health.

Abstracts from the conference will be published in the Journal.

Following the success of this conference, the EACE is planning their 33rd Annual Scientific Meeting in Krakow, Poland, for late spring of 2021. The 2021 ICEC is scheduled to be held in Toronto on October 6-8, 2021. We will keep you informed about more details of these two conferences as the dates draw closer.

I look forward to seeing you all at future conferences and sharing our goal of decreasing the burden of cancer through education.

Wishing you and your families well.

Publisher's Note Springer Nature remains neutral with regard to jurisdictional claims in published maps and institutional affiliations. 